AGRICULTURE AND BIOLOGY JOURNAL OF NORTH AMERICA

ISSN Print: 2151-7517, ISSN Online: 2151-7525

(C) 2011, ScienceHu $\beta$, http://www.scihub.org/ABJNA

\title{
Mycorrhizosphere development and management: The role of nutrients, micro-organisms and bio-chemical activities
}

\author{
Kriti Kumari Dubey and M.H. Fulekar*
}

\author{
Environmental Biotechnology Laboratory, Department of Life Sciences, University of Mumbai, \\ Santacruz (E), Mumbai-400 098, India \\ *corresponding author: mhfulekar@yahoo.com: Tel: +91-2226528847, Fax: +91-2226526053
}

\begin{abstract}
The selection of pollutant tolerant plant, rhizosphere process and their proper management and establishment is crucial for successful phytoremediation experiment. To carry out rhizospheric bioremediation studies under the influence of mycorrhiza for the better survival of the plants, a cost effective method for the mass production of mycorrhizal inoculum is prerequisite. In the present research study, soil based mycorrhizal inoculum has been developed using Sorghum as a host plant in green house for a period of 75 days using pot culture technique. The physicochemical characteristics, mycorrhizal status, Acid phosphatase activity (ACP), alkaline phosphatase activity (ALP), dehydrogenase activity (DHA) along with the number and diversity of bacteria, fungi and actinomycetes were assessed at a frequency of 15 days in the rhizospheric soil samples. Development of mycorrhizae was characterized by AM spore count and colonized root length percentage (\%CRL) in Sorghum. Our data showed that soil nitrogen $(\mathrm{N})$, organic carbon $(\mathrm{C})$, organic phosphorus ( $\mathrm{Po}), \mathrm{C} / \mathrm{N}$ and N/P ratio significantly increased with an increase in spore count and AM colonization. ACP, ALP and microbial activity (as represented by viable counts and DHA) were also found to be increasing during the process of mycorrhiza development. Thus developing mycorrhizae induce a series of changes in nutrient availability, microbial composition and enzymatic activities in the soil that may determine the outcome of a phytoremediation attempt. Developed mycorrhizal inoculum in the present study can contribute in establishing an effective mycorrhizosphere that can provide the environment for enhanced degradation of pollutants present in the soil.
\end{abstract}

Keywords: Mycorrhiza, Sorghum, Acid phosphatase activity, Alkaline phosphatase activity

\section{INTRODUCTION:}

Plant-assisted bioremediation or phytoremediation holds promise for in situ treatment of polluted soils. Pollutant toxicity, adverse soil conditions (e.g. low organic matter content, poor soil structure), water stress and nutrient deficiency are typical problems challenging the establishment of Phytoremediation strategies in contaminated soil. Enhancement of phytoremediation processes requires a sound understanding and management of the complex interactions in the mycorrhizosphere. To ameliorate nutrient limitations and pollutant toxicity advantage can be taken in developing and managing rhizosphere. The association of plants with mycorrhizal fungi can have strong influences on the responses of microbial activities to $P$ fertilization, due to the fact that these fungi are able to enhance $P$ availability to and uptake by plants inoculated with mycorrhiza [Smith and Read, 1997]. Following inoculation, AM fungi influence microbial population and activity and consequently nutrient dynamics in the soil through the release of organic compounds. AM fungi may directly or indirectly contribute to soil C and $\mathrm{N}$ dynamics. The activity of $\mathrm{AM}$ fungus in the mycorrrhizosphere could be a source of different soil enzymes required for biochemical reactions. There are reports indicating that soil enzymatic activities, such as phosphatases, dehydrogenases are increased by AM fungus inoculation [Kothari et al.1990].Very small percentage of the soil $P$ is labile and moderately labile organic $P \quad(P o)$, Acid phosphatase activity (ACP) allows the use of less readily available $\mathrm{P}$ forms hydrolyzing $\mathrm{Po}$ to $\mathrm{Pi}$ [Clarholm,1997]. Most of the Po mineralizing activity occurs at the rhizosphere where phosphatases released from plant roots [Helal and Dressler, 1989] and soil microorganisms [Asmar et al., 1995] are present. Some authors even assert that the soil ALP activity increases due to the presence of mycorrhizal hyphae and AM mycelia may have $P$ mineralizing activity [Jaychandran et al.1992] [Tarafdar and Marshner,1994]. ACP [Fox and Comerford, 1992] as 
well as AM colonization [Joner and Jakobsen, 1995] can be induced by $\mathrm{P}$ deficiency. Furthermore, rhizospheric microorganisms and AM can synergistically contribute to plant $\mathrm{P}$ nutrition [Toro et al., 1996] [Singh and Kapoor, 1998]. Thus AM colonization, soil microorganisms, ACP and ALP in the rhizosphere are considered as crucial mechanisms for $\mathrm{P}$ availability and plant $\mathrm{P}$-uptake. Mycorrhiza establishment changes both quantitatively and qualitatively the microbial populations in the rhizosphere. Plants grown in mycorrhizospheric soil are often more competitive and better able to tolerate environmental stresses than normally grown plants, potentially enhancing pollutant availability and plant tolerance [Gaur and Adholeya, 2004].Mycorrhizosphere development process by the inoculation of mycorrhiza has been reported to modify the quality and abundance of rhizospheric microflora and alter overall rhizosphere microbial activity which may be responsible for the bioremediation in the contaminated soil (Khan,2006) mycorrhizosphere provide the better water and nutrient acquisition by the plants .Mycorrhiza were also shown to act as filters, blocking toxic compounds within their mycelium resulting into reduced toxicity to plants. Moreover, they influence the physiology of their host plant making them less vulnerable to pathogens, soil pollution, salinity, drought and a number of other environmental stress factors. Mycorrhizal strains have shown improved tolerance to toxic compounds, hence said to optimize the success of phytoremediation (www.kosmos.icm.edu.pl/PDF/2002/185a.pdf)

For rhizospheric remediation studies development of cost effective method for the mass production of mycorrhizal inoculum is of great importance. The main objective of the present study was (i) to develop cost effective and reliable mycorrhizal soil inoculum which can be used for laboratory scale and field scale phytoremediation strategies and (ii) to study and understand the physicochemical, mycorrhizal, microbial and biochemical activities and their complex interactions in the rhizosphere during development of mycorrhizal soil inoculum which will be beneficial for designing phytoremediation technologies with improved predictable, remedial success.

\section{MATERIAL AND METHODS:}

Test plant, Soil, and experimental design: Sorghum was used as collateral host for the development of mycorrhizal soil in the green house. Soil was collected from a depth of about $0-15 \mathrm{~cm}$ along the banks of Surya River, Palghar (located 100 $\mathrm{km}$ from Mumbai).Plant tissues and stones were carefully removed from the soil prior to drying under laboratory conditions. The soil was screened through $2 \mathrm{~mm}$ stainless steel sieve, and was characterized for its physico-chemical parameters. A green house experiment was set up for the development of mycorrhizal soil inoculum under controlled environmental conditions. Before planting, Sorghum seeds were surface sterilized with $1 \%$ mercuric chloride solution for 1 minute and rinsed with sterile distilled water. In a growth chamber, seeds were placed on moist filter papers in petri dishes and germinated in the dark at $25^{\circ} \mathrm{C}$. Ten 3-day-old seedlings of uniform size $(1.5-2 \mathrm{~cm})$ were transferred into each plastic pots containing $7.5 \mathrm{~kg}$ of soil and sand mixture (3:1 ratio) and 750 grams of mixed starter inoculum, in the form of mixture of spores, soil, external mycelium and root fragments obtained from IARI, microbiology division India. The average air temperature in the greenhouse was $25-30^{\circ} \mathrm{C}$. Plants were grown under natural light in plastic pots for 75 days and after that left for rhizodegradation for 15 days in a greenhouse. Soil and root sampling was done at regular interval of 15 days till the inoculum development process completed. Collected soil samples were characterized for its physico-chemical properties, microbial and enzymatic activities. The extent of mycorrhizal infection was determined by the spore counting and percentage of root length colonized (\%CRL) by mycorrhizal fungi.

Soil sampling: Sampling of soil was done at regular intervals of 15 days; all soil samples were stored at $4^{\circ} \mathrm{C}$ until analyzed. Soil samples were first sieved (< $2 \mathrm{~mm}$ ) and afterwards divided into four aliquots. One aliquot of each soil sample was dried at $105^{\circ} \mathrm{C}$ for soil water content determination. A second soil aliquot was stored at $4^{\circ} \mathrm{C}$ for $\mathrm{Pt}$, Po determination and total soil organic carbon (C) analyses. A third soil sample aliquot was used to determine soil $\mathrm{pH}$, and finally, the rest of each soil sample was kept without drying at 4 ${ }^{\circ} \mathrm{C}$ until soil enzymatic activities determination.

Soil physico-chemical analyses: The collected soil was characterized for its physico-chemical properties. The physico-chemical parameters were measured by standard methods. The $\mathrm{pH}$ and electrical conductivity (EC) were measured after 20 min of vigorously mixing the soil samples at 1: 2.5 in deionized water, the $\mathrm{pH}$ and electrical conductivity (EC) were measured using digital meters [Deluxe water and soil analysis kit, Model 191E]. Total nitrogen, sodium and potassium were determined according to APHA 
method [APHA, 1998]. Total phosphorus content (Pt) [Dick and Tabatabai, 1997] and Organic phosphorus content $(\mathrm{Po})$ of the soil was determined [Olsen and Sommers, 1982].

Determination of spore count and the mycorrhizal colonization: The spores were isolated by wet sieving and decanting technique [Gerdemann and Nicholson, 1963] from the rhizospheric soil along the roots of Sorghum. One fifth of a container was filled with rhizospheric soil and mixed well with water until all soil aggregates are dispersed, an even suspension was made and kept overnight undisturbed. Suspension was decanted through 4 sieves of different sizes arranged in the order of $710 \mu \mathrm{msieve}, 250 \mu \mathrm{m}$ sieve, $105 \mu \mathrm{m}$ and lastly $50 \mu \mathrm{m}$ sieve along with continuous washing with a jet of water under the tap. The washings of $50 \mu \mathrm{m}$ sieve were collected in a beaker. The presence of spores was verified microscopically in a Petri dish. To determine AM colonization, Sorghum root samples collected were carefully rinsed, cleared and trypan blue stained [Philips and Hayman, 1970]. Roots from each replicates were carefully separated and washed with de-ionized water for microscopic examination. Three subsamples of 20 randomly selected $1 \mathrm{~cm}$ rootlets per site were cleared in $10 \% \mathrm{KOH}$ for $24 \mathrm{~h}$ and in $10 \% \mathrm{H}_{2} \mathrm{O}_{2}$ for $1 \mathrm{~h}$, acidified in $1 \% \mathrm{HCl}$ for 15 min and stained with Trypan blue. AM colonization in these samples was quantified in a microscope at 10X magnification and expressed as \%CRL. Living roots were identified on the basis of a turgid appearance and possessing white cortical cells. The morphological-anatomical mycorrhizae types were distinguished by macroscopic characteristics of the fungal mantle, such as colour, surface appearance, presence of emanating hyphae and hyphal strands, as well as microscopic features such as mantle type and hyphal connections.

Microbial characterization: Microbial number and diversity was assessed in the developing mycorrrhizosphere zone. Bacterial, fungal and actinomycetes colony forming units (CFU) were counted using the standard dilution plate technique of fresh soil suspension on selective media. Bacteria were determined on tryptic soy agar [Martin, 1975]. Fungi were estimated on rose Bengal agar [Martin, 1950] and actinomycetes colonies were counted on starch casein agar medium. Colonies were counted and identified on the appropriate dilutions after 2, 5 and 7 days, respectively, incubation at $25^{\circ} \mathrm{C}$. The results are reported as log of bacterial, fungal or actinomycetes CFU per gram of dry soil.
Rhizospheric enzymatic determinations: In the laboratory, subsamples were taken from bulk samples and were further homogenized. Large roots or shells were removed and wet soil samples were added to polypropylene centrifuge tubes for analysis of enzymatic activities. For alkaline and acid phosphatase enzymatic activity the base substrate used was p-nitrophenol bound with phosphate [Tabatabai and Brenmer, 1969]. The artificial substrate $(1 \mathrm{~mL}, 0.05 \mathrm{M})$, toluene to inhibit microbial growth during incubation, a pH buffer $(\mathrm{pH} 11$ for alkaline phosphatase and $\mathrm{pH} 4.5$ for acid phosphatase) were incubated in closed polypropylene centrifuge tubes at $37^{\circ} \mathrm{C}$ for $1 \mathrm{~h}$. At the end of incubation, enzyme activity was stopped by addition of $4 \mathrm{~mL}$ of $0.5 \mathrm{M} \mathrm{NaOH}$; the mixture was filtered and the extract was analyzed using a UV-VIS spectrophotometer at $420 \mathrm{~nm}$. Absorbance of filtrates was compared with p-nitrophenol standards. To account for non enzymatic substrate hydrolysis, values for controls were subtracted from sample replicates. For DHA activity 2, 3, 5triphenyltetrazolium chloride (TTC) was added as substrate to the fresh moist soil samples and incubated at $37^{\circ} \mathrm{C}$ for 24 hours. After incubation the triphenyltetrazoliumformazan (TTF) formed was extracted, centrifuged and estimated spectrophotometrically at $485 \mathrm{~nm}$. Dehydrogenase activity is expressed as microgram of TTF released per gram of dry soil per 24 hours [Casida et al., 1964].

\section{RESULTS AND DISCUSSION:}

In the present study mycorrhizal soil inoculum was developed by pot culture using Sorghum plant as host in green house and during the process of mycorrhiza development soil samples were characterized for its physico-chemical, mycorrhizal, microbial and biochemical properties and their interactions in rhizosphere.

Soil physico-chemical analyses: It is important to consider the physicochemical characteristics of the soil besides nutrient concentration because both effects AM growth. It has been established that nutrients and phosphorus solubility effects the mycorrhization. The physico-chemical characterization of the soil was done at the time of collection, during development of mycorrhizal inoculum and after development of mycorrhizal inoculum (table 1 ). Initially the $\mathrm{pH}$ of the soil was 6.4 (slightly acidic) which increased to 7.3 (slightly basic), while electrical conductivity was found to be in range of 0.34 to 0.45 . Moisture content was maintained in the range of 42.2 to 48.1 for effective mycorrhization. 
Organic carbon content of collected soil was very low (72 $\mathrm{gm} / \mathrm{kg}$ ) which increased to $259 \mathrm{gm} / \mathrm{kg}$ after development. Significant increase in soil $\mathrm{N}$ and Po content was also observed, Po, which is considered to be plant available, was also very low in the soil sample. There was no change in the Pt content of the soil during the process, but increase in Po which increased from 0.19 to 0.42 due to microbial immobilization. Sodium and potassium content was found to be almost remained constant, while there was increase in $\mathrm{C} / \mathrm{N}$ ratio from 12.41 to 30.83 , and $\mathrm{N} / \mathrm{P}$ ratio which increased from 8.06 to 10.73 (table 2) after successful mycorrhizal colonization.

Table 1. Physico- Chemical Characteristics of Soil samples collected from the site, during inoculum development (in ranges) and of the developed mycorrhizal inoculum.

\begin{tabular}{|l|c|c|c|}
\hline \multicolumn{1}{|c|}{ Soil Parameters } & $\begin{array}{c}\text { Soil samples } \\
\text { collected from } \\
\text { site }\end{array}$ & $\begin{array}{c}\text { During inoculum } \\
\text { development }\end{array}$ & $\begin{array}{c}\text { Mycorrhizal } \\
\text { inoculum }\end{array}$ \\
\hline $\mathrm{pH}$ & 6.4 & $6.4-7.3$ & 7.3 \\
\hline Moisture Content & 42.4 & $40.4-48.1$ & 42.2 \\
\hline Electrical Conductivity (meq/100 gm) & 0.38 & $0.34-0.44$ & 0.34 \\
\hline Organic Carbon(gm/kg) & 72.0 & $72-259$ & 259 \\
\hline Total Nitrogen $(\mathrm{gm} / \mathrm{kg})$ & 5.8 & $5.8-8.4$ & 8.4 \\
\hline Total Phosphorous(Pt) $(\mathrm{gm} / \mathrm{kg})$ & 0.72 & $0.71-0.81$ & 0.81 \\
\hline Organic phosphorus (Po)(gm/kg) & 0.19 & $0.19-0.42$ & 0.42 \\
\hline Potassium (mg/Kg) & 21 & $21-24$ & 22 \\
\hline Sodium (mg/Kg) & 23 & $2.3-2.8$ & 32 \\
\hline C/N & 12.41 & $12.41-30.83$ & 30.83 \\
\hline N/P & 8.06 & $8.06-10.37$ & 10.73 \\
\hline Spore count/100gm of soil & 10 & $10-546$ & 546 \\
\hline VAM colonization & Absent & $0-78$ & 78 \\
\hline
\end{tabular}

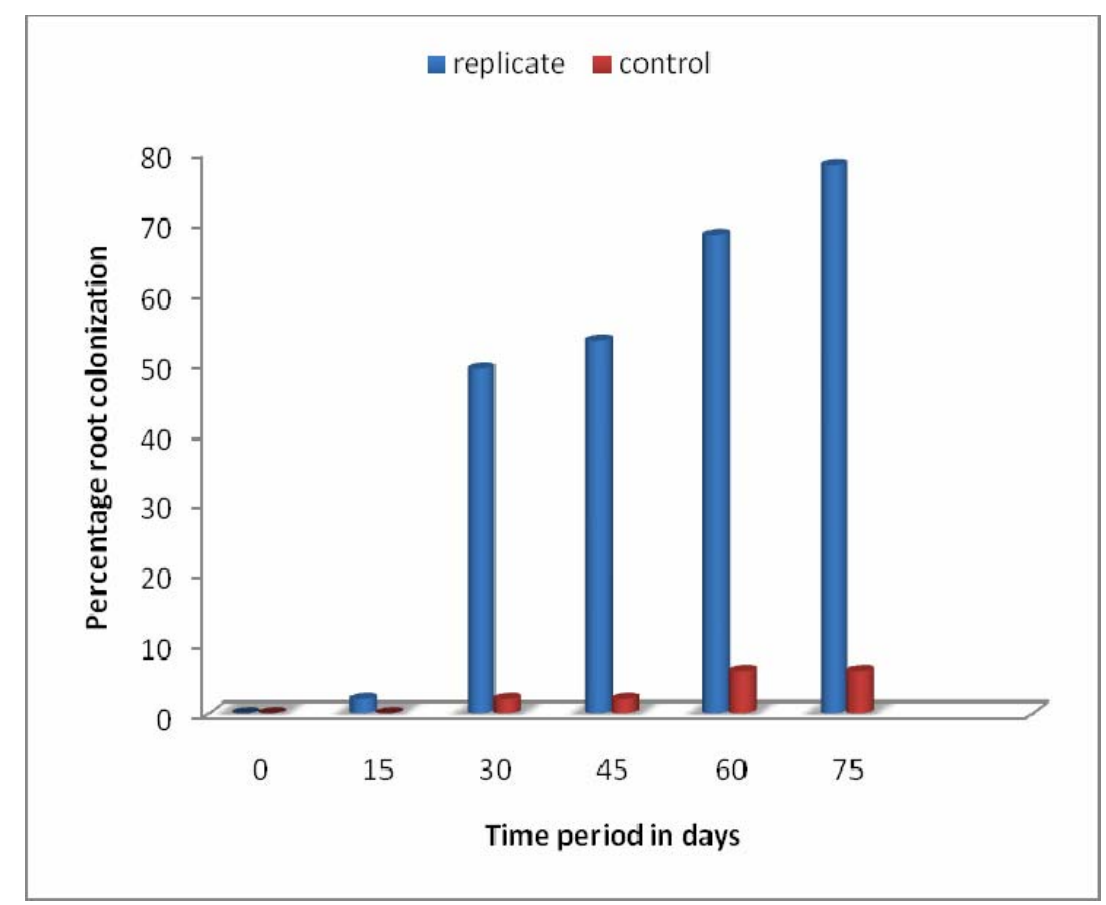

Fig 1. Increase in Sorghum root colonization during development of mycorrhizal soil inoculum. 


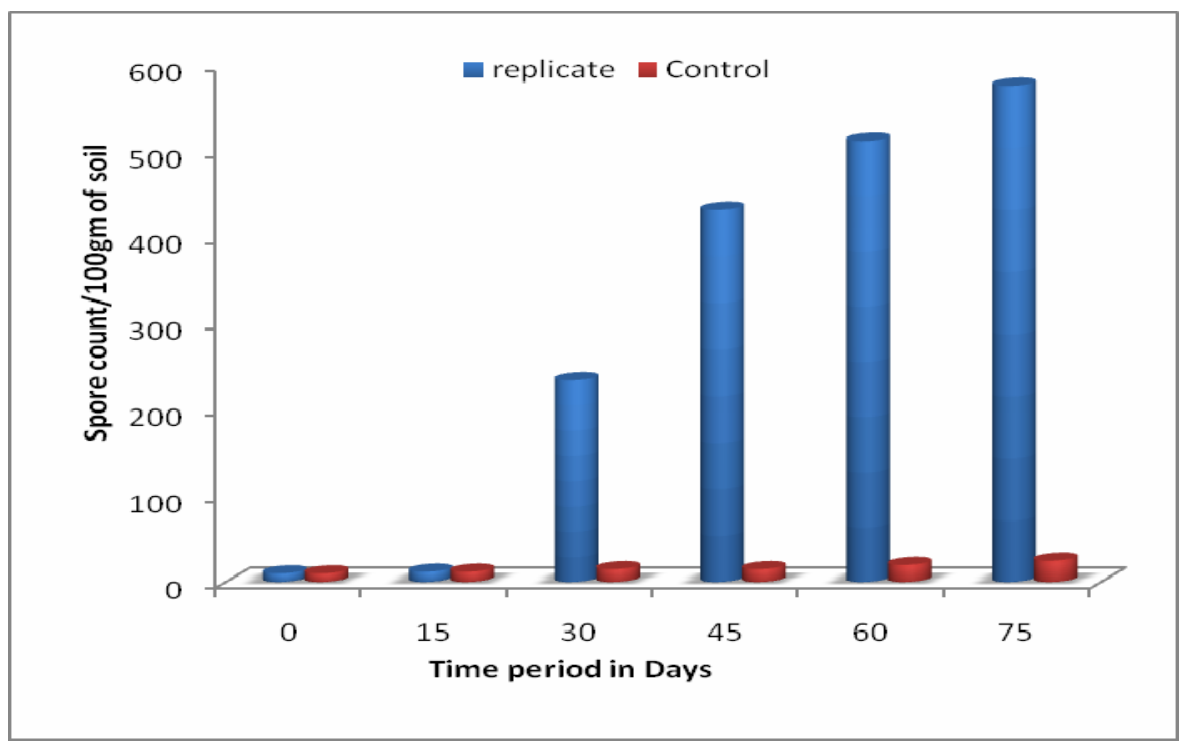

Fig 2. Increase in AM spore count during development of mycorrhizal soil inoculum.

Table 2. Physico-chemical characterization of developing mycorrhizal soil inoculum at the time interval of 15 days during development of mycorrhizal soil inoculum.

\begin{tabular}{|c|c|c|c|c|c|c|c|c|c|c|c|}
\hline 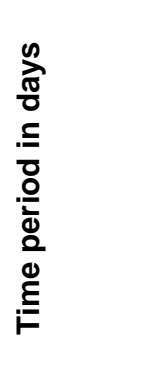 & $\frac{I}{2}$ & 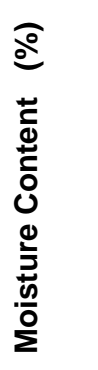 & 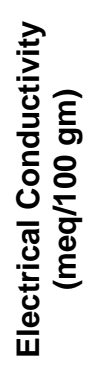 & 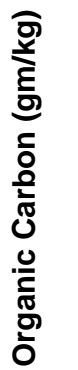 & 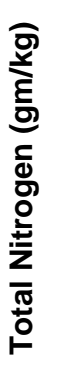 & 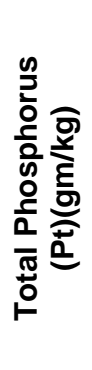 & 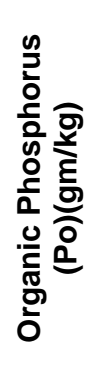 & 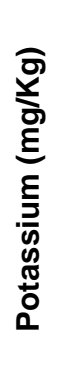 & 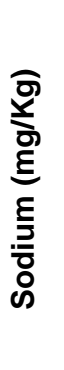 & $\frac{z}{U}$ & $\frac{n}{z}$ \\
\hline 0 & 6.4 & 42.4 & 0.38 & 72 & 5.8 & 0.72 & 0.19 & 21 & 2.3 & 12.41 & 8.06 \\
\hline 15 & 6.8 & 40.4 & 0.37 & 84 & 6.2 & 0.71 & 0.21 & 23 & 2.4 & 13.55 & 8.73 \\
\hline 30 & 6.8 & 48.1 & 0.45 & 136 & 6.2 & 0.72 & 0.29 & 22 & 2.8 & 21.94 & 8.61 \\
\hline 45 & 7.0 & 46.8 & 0.44 & 160 & 7.3 & 0.77 & 0.31 & 23 & 2.6 & 22.07 & 9.48 \\
\hline 60 & 7.2 & 45.4 & 0.42 & 184 & 8.3 & 0.81 & 0.36 & 24 & 2.3 & 22.17 & 10.25 \\
\hline 75 & 7.3 & 42.2 & 0.34 & 259 & 8.4 & 0.81 & 0.42 & 22 & 3.2 & 30.83 & 10.37 \\
\hline
\end{tabular}

\section{Spore count and Mycorrhizal status:}

The mycorrhizal characterization was done by spore count enumeration and determination of \%CRL. The number of spores present in native soil was very negligible initially, after development of mycorrhizal soil spore count was $546 / 100$ grams of soil with $78 \%$ root colonization (fig. 1 and fig. 2 ) High levels of AM colonization were observed with low nutrient diffusion rate, such as $\mathrm{P}$, decreasing plant availability.
Accordingly, our results showed AM colonization was higher, when $\mathrm{P}$ mineralization was lower and microbial immobilization was higher. Thus, AM colonization was higher when $\mathrm{P}$ was less available for plant uptake.

Enzymatic results and viable plate counts: Colonization of plant roots by AM fungi can affect microbial communities and biochemical activities associated with the roots, mycorrhizae can interact 
and modify the microbial communities present in the soil, by changes in root exudation patterns or fungal exudates, therefore bacterial, fungal and actinomycetes abundance and diversity was assessed during the mycorrhizal soil inoculum development process. Bacterial CFU increased along the period which decreased at the time of harvesting, while marginal increase was seen in fungal and actinomycetes CFU (fig 3). The diversity of bacterial, fungal and actinomycetes genera present in the developing mycorrhizosphere were also assessed. (Table 3)

Table 3. Microbiota of developing mycorrhizal soil inoculum.

\begin{tabular}{|c|c|c|}
\hline Bacterial genera & Fungal genera & Actinomycetes genera \\
\hline Alcaligenes spp. & Aspergillus flavus & Micromonospora spp. \\
Bacillus spp. & Aspergillus fumigatus & Nocardia spp. \\
Sarcina spp. & Aspergillus niger & \\
Serratia spp. & Penicillium spp. & \\
Streptococcus spp. & Rhizopus spp & \\
\end{tabular}

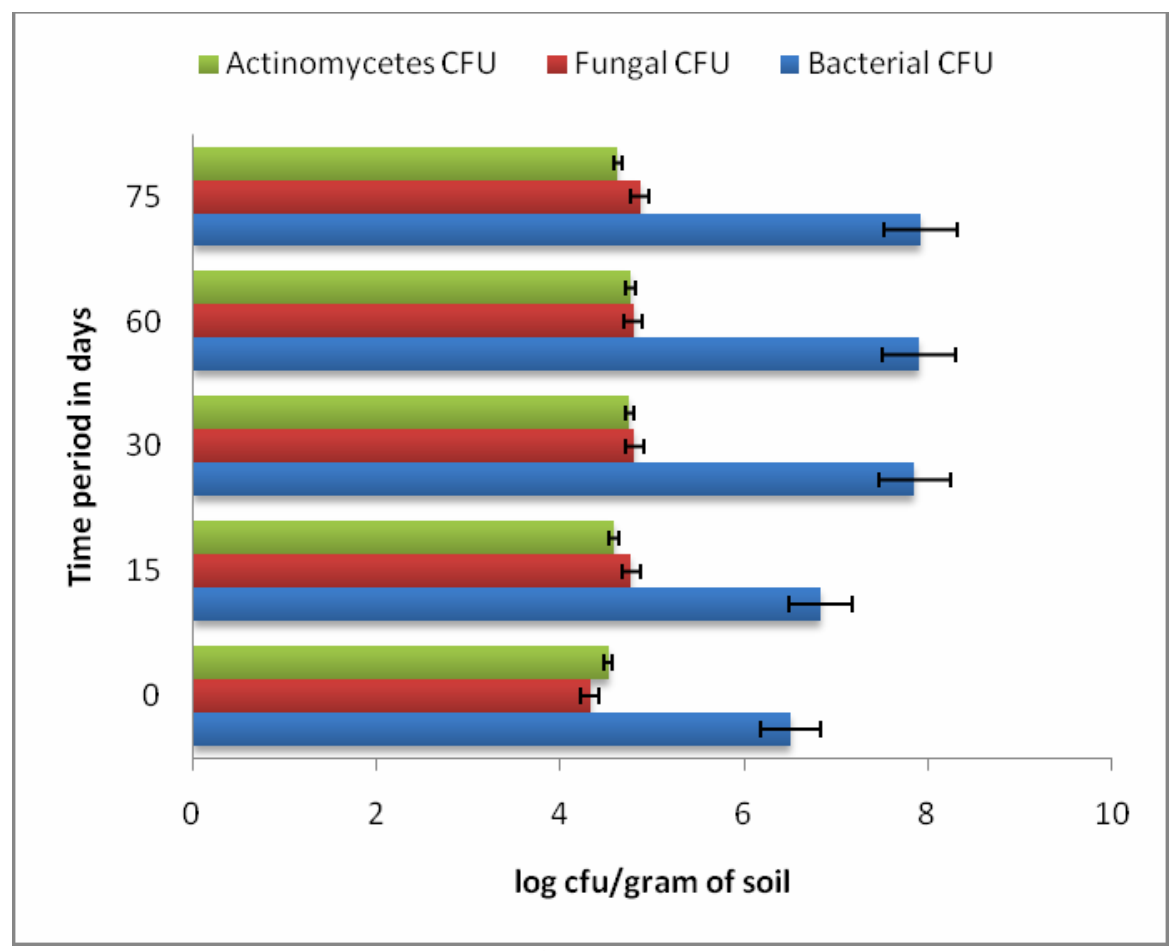

Fig 3. Changes in bacterial, fungal and actinomycetes CFU during development of mycorrhizal soil inoculum.

The activity of AM fungus and microorganisms present in the mycorrhizosphere could be a source of different soil enzymes required for biochemical reactions. Microbial activity can be represented by DHA, Dehydrogenases are not expected to be free in soil, therefore, DHA expresses living cell activity and that is why it is an indicator of biological activity [Frankenberg and Dick, 1883]. In an attempt to relate DHA with indicator of soil microbial activity, soil bacteria, fungi, and actinomycetes were quantified. 
DHA as expected show same pattern as viable plate counts. DHA significantly increased during the development of mycorrhizal soil at different time intervals (fig 4). DHA can correlate with changes in the microbial biomass due to long-term soil amendment [Goyal et al., 1993]. The importance of soil microorganisms in the present study has been evaluated taking into account viable counts and activity of soil microorganisms (DHA). Furthermore, microorganisms in the rhizosphere may contribute to $P$ nutrition through the synthesis and release of phosphatases when $P$ is not available. The increase in DHA and bacterial counts during the development of mycorrhizal soil, suggests that the increase in ACP during development period is mediated by rhizospheric microorganisms Mycorrhizal colonization clearly led to distinctive increases in the activities of enzymes involved in $\mathrm{P}$ dynamics. ACP and ALP significantly increased during the development of mycorrhizal soil. However, initially this increase was proportionally higher for the ACP (fig. 5) while in later stages after successful mycorrhizal colonization there was increase in ALP (fig. 6)

These results suggest that $P$ mineralization, as expressed by ACP, increases during the development period, when plant nutrient uptake and nutrient leaching are higher. There was increase in microbial $P$ mobilization during the development period which was confirmed by a decreasing ratio of acid to alkaline phosphatases in the soil.

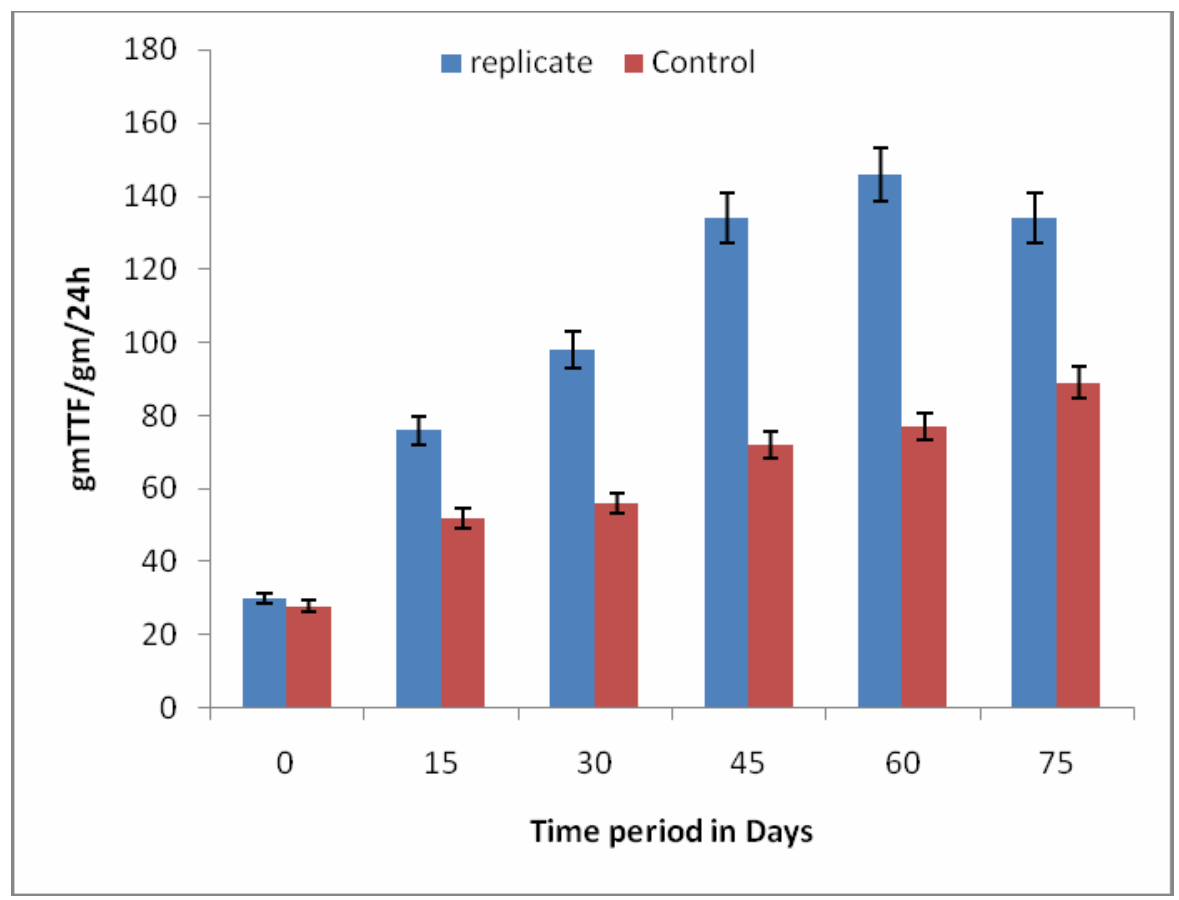

Fig 4.Changes in dehydrogenase activities due to microbial activities during development of mycorrhizal soil. 
Agric. Biol. J. N. Am., 2011, 2(2): 315-324

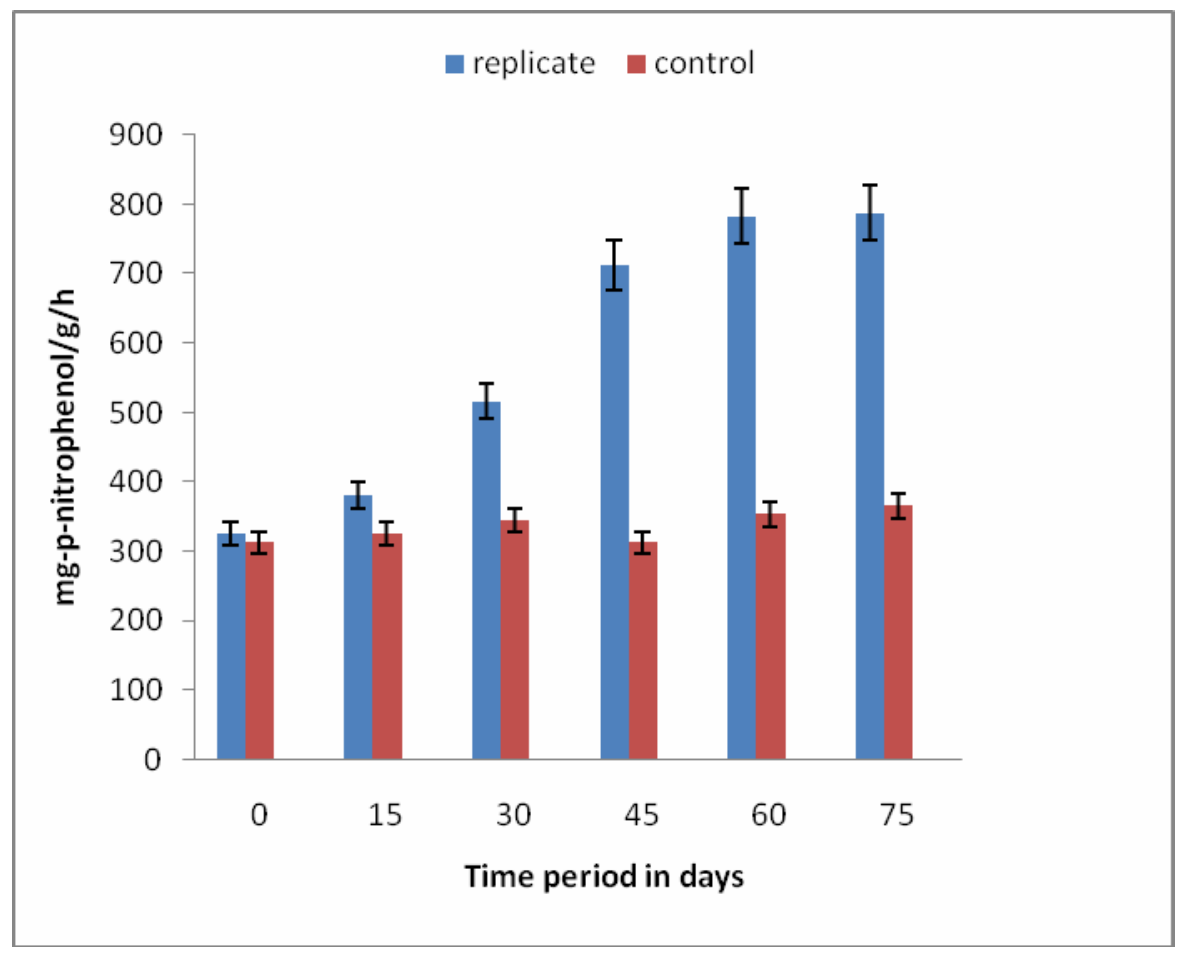

Fig 5. Acid phosphatase activities (ACP) during development of mycorrhizal soil inoculum.

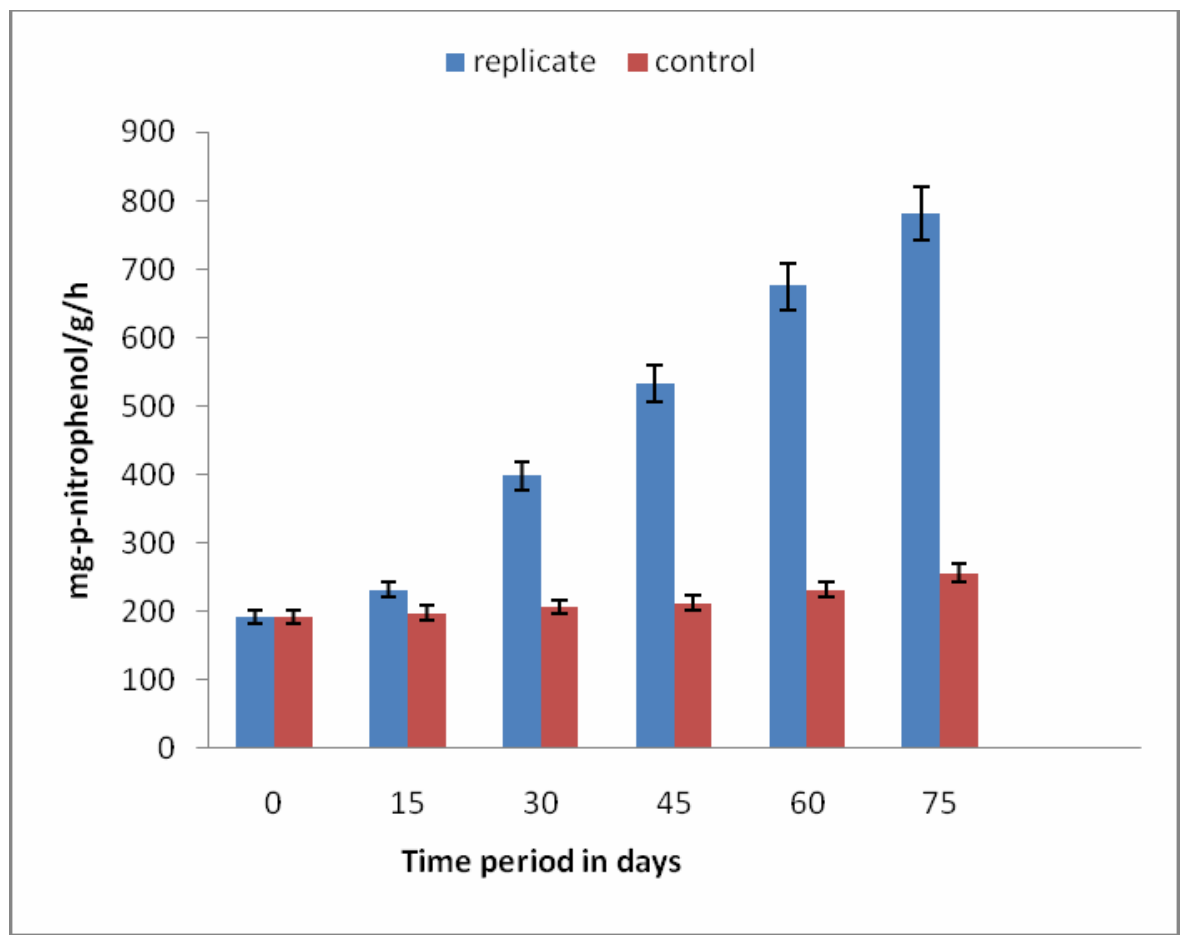

Fig 6. Alkaline phosphatase activities (ALP) during development of mycorrhizal soil inoculum. 


\section{CONCLUSIONS:}

In the present study, a green house pot experiment is described for the development of mycorrhizal soil inoculum in which $P$ mineralization, microbial community and AM colonization seem to be working in synchrony to overcome the $\mathrm{P}$ availability (necessary for colonization) during inoculum development process. The research study highlights that the portion of $\mathrm{Po}$ on $\mathrm{Pt}$ increased with higher organic $\mathrm{C}$ and $\mathrm{N}$ concentration in the soil. Mycorrhizal colonization was detected on Sorghum at the time of harvesting in all replicates. Initially, colonization percentage was very low, but after $30^{\text {th }}$ day root colonization was $49 \%$ which increased to $78 \%$ at the time of harvesting. In rhizospheric soil of Sorghum close relationship between colonization densities of bacterial, fungal and actinomycetes and the activities of acid and alkaline phosphatase were observed. The increase in dehydrogenase activities in rhizospheric soil can be attributed to increase in microbial CFU. Mycorrhizal colonization and rhizospheric microorganisms function in concert to promote the phosphatase activities in soil which in turn led to $P$ availability at different stages of inoculum development. Mycorrhizal inoculum developed by pot culture technique can be used for rhizospheric bioremediation process [Korade and Fulekar, 2009]. The mycorrhizal inoculum developed in the present research work was obtained with establishment of mycorrhizosphere supporting survival and growth of microorganisms with high phosphatase activities and increased organic carbon and nutrients allocation. Mycorrhizosphere constitutes an important niche for microbial activity. Microbial interactions in the mycorrhizosphere are the determinants of soil fertility and environmental health, our understanding of these interactions therefore has implications for sustainable soil management. An improved understanding of the rhizosphere will help in designing rhizospheric remediation technologies at laboratory bench scale to the full complexity and heterogeneity of field applications, which can further help to enhance degradation of pollutants in the soil.

\section{REFERENCES:}

APHA, AWWA, WPCF, Standard Methods for the Examination of Water and Wastewater, American Public Health Association/American Water Works Association/Water Environmental Federation, Washington DC, 1998.

Asmar, F., Singh, T., Nielsen, G., Nielsen, N.E.: Barley genotypes differ in activity of soluble extracellular phosphatase and depletion of organic phosphorus in the rhizosphere soil. Plant Soil 1995, 172: 117-122.
Casida, L.E., Klein, D.A., Santoro, T. : Soil dehydrogenase activity. Soil Science 1964, 98: 371-376.

Clarholm, M.: Microbial biomass $P$, labile $P$, and acid phosphatase activity in the humus layer of a spruce forest, after repeated additions of fertilizers. Biol. Fert. Soils 1993, 16: 287-292.

Dick, W.A.., Tabatabai M.A., An alkaline oxidation method for determination of total phosphorus in soils, Soil Sci.Soc.Am.J 1997, 511-514.

Fox, T.R., Comerford NB: Rhizosphere phosphatase activity and phosphatase hydrolyzable organic phosphorus in two forested spodosols. Soil Biol. Biochem.1992, 24: 579-583.

Frankenberger, J.W.T., Dick, W.A.: Relationship between enzyme activities and microbial growth and activity indices in soil. Soil Sci. Soc. Am. J.1883, 47: 945-951.

Gaur, A. and Adholeya A.: Prospects of arbuscular mycorrhizal fungi in phytoremediation of heavy metal contaminated soils. Current Science 2004, 86(4): 528533.

Gerdemann, J.W. and Nicholson, T.H.: Spores of mycorrhizal endogone species extracted from soil by wet sieving and decanting. Transactions of the British Myological Society1963, 46: 235-244.

Goyal, S., Mishra, M.M., Dhankar, S.S., Kapoor KK, Batra R: Microbial biomass turnover and enzyme activities following the application of farmyard manure to field soils with and without previous long-term applications. Biol. Fert. Soils 1993, 15: 60-64.

Helal, H., Dressler, A: Mobilization and turnover of soil phosphorus in the rhizosphere. Z. Pflanzenernahr. Bondenk. 1989, 152: 175-180.

Jayachandran, K., Schwab, A.P., Hetrick, B.A.: Mineralization of organic phosphorus by vesiculararbuscular mycorrhizal fungi. Soil Biol. Biochem.1992, 24: 897-903.

Joner, E.J., Jakobsen, I.: Growth and extracellular phosphatase activity of arbuscular mycorrhizal hyphae as influenced by soil organic matter. Soil Biol. Biochem. 1995, 27: 1153-1159.

Khan, A.G., 2006. Mycorrhizoremediation-an enhanced form of phytoremediation. Journal of Zhejiang University Science B 7(7): 503-514.

Kothari, S.K., Marschner, H., Romheld, V.: Direct and indirect effects of VA mycorrhizae and rhizosphere microorganisms on mineral nutrient acquisition by maize (Zea mays L.) in a calcareous soil. New phytol. 1990, 116: 637-645.

Martin, J.K.: Comparison of agar media for counts of viable soil bacteria. Soil Biol. Biochem. 1975, 7: 401-402.

Martin, J.P.: Use of acid. Soil Sci. 1950, 69: 215-232.

Olsen, S.R., Sommers, L.E.: Phosphorus. In: Page, A.L. (Eds.), Methods of Soil Analysis. Part 2. Chemical and Microbiological Properties. ASA, Madison1982, 403430.

Phillips, J.M., Hayman, D.S.: Improved procedures for clearing roots and staining parasitic and vesiculararbuscular mycorrhizal fungi for rapid assessment of infection. Trans. Brit. Mycol. Soc.1970, 55: 158-161. 
Agric. Biol. J. N. Am., 2011, 2(2): 315-324

Singh, S., Kapoor, K.K.: Effects of inoculations of phosphate-solubilizing microorganisms and an arbuscular mycorrhizal fungus on mungbean grown under natural soil conditions. Mycorrhiza 1998: 249253

Smith, S.E., Read DJ: Mycorrhizal symbiosis. Academic press, San Diego.1997

Tabatabai, M.A., Brenmer, J.A., 1969. Use of p-nitrophenyl phosphate for assay of soil phosphatase activity. Soil Biol. Biochem. 1969, 1:301-307.
Tarafdar, J.C., Marshner, H.: Phosphatase activity in the rhizosphere of VA mycorrhizal wheat supplied with inorganic and organic phosphorus. Soil Biol. Biochem. 1994, 26: 387-395.

Toro, M., Azcón, R., Herrera, R.: Effects of yield and nutrition of mycorrhizal and nodulated Pueria phaseoloides exerted by P-solubilizing rhizobacteria. Biol. Fert. Soils 1996, 21: 23-29. 